\title{
Seroprevalence of hepatitis B infections among blood donors in Bijapur district Karnataka - Retrospective study
}

\author{
Prakash Murigeppa Patil', Vijaylaxmi S. Patil' ${ }^{2}$ Balasaheb R. Yelikar ${ }^{3}$, Mihir J. Bhalodia ${ }^{4}$, \\ Muttappa R. Gudadinni ${ }^{5}$, Mohd Shannawaz ${ }^{6}$
}

\begin{abstract}
${ }^{1}$ Associate Professor*, ${ }^{2}$ Assistant Professor, ${ }^{3}$ Professor \& Head, ${ }^{4}$ Post Graduate, Department of Pathology, ${ }^{5,6}$ Associate Professor and Lecturer, Department of Community Medicine, BLDE University, Shri B.M. Patil Medical College, Hospital \& Research Center. Bijapur - 586103.

Karnataka, India
\end{abstract}

\section{A B S T R A C T}

Objectives: To determine the seroprevalence of HBsAg in the prevalence of HBsAg positivity among male and female blood donors. Materials and Methods: A retrospective study was conducted in blood bank. Voluntary and replacement blood donors including male and female donors over a period of two years six month to assess the prevalence of hepatitis B virus infection. ELISA method and alternatively Hepacard kit were used for screening the donors. Results: A retrospective study was carried on 7,018 blood donors out of which males were 5,936 and 1,082 were females. The prevalence of HBsAg sero positivity in 2011 July to December in male donors were $2.8 \%$; in female donors $0.0 \% ; 2012$ January to December in male donors were $2.9 \%$ and female donors were $0.3 \% ; 2013$ January to December in male donors were $1.8 \%$ and Female donors were $0.0 \%$. Overall prevalence was estimated to be $7.8 \%$. Conclusion: Hepatitis B infection remains a significant public health problem in India and its seroprevalence was more as compared to other transfusion transmitted infections, especially in younger age group. The increasing prevalence of HBsAg can be reduced by more sensitive screening assays.

Key words: Hepatitis B infection, Seropositivity, Prevalence, Blood donors
Access this article online

Website:

http://nepjol.info/index.php/AJMS

DOI: 10.3126/ajms.v613.10862

\section{INTRODUCTION}

Hepatitis B infection has become one of the major global health problems. Hepatitis B causes an estimated 1-2 million deaths per year worldwide. ${ }^{1,2}$ It is estimated that there are 300 million carriers of Hepatitis B virus in the world, countries are classified on the basis of endemicity of Hepatitis B virus infection. Highest carriers in equatorial Africa $8 \%$ or more and in South East Asia, China, parts of South America intermediate 2-7\% in Eastern Europe, middle East, South Asia carrier rate low $<2 \%$ in developed countries as North America and Australia incidence countries. ${ }^{1}$ The prevalence of chronic hepatitis B infection in India ranges from $2-10 \%$ as shown by different studies. ${ }^{2}$

The screening of donors help in determining safe transfusion of the blood and its products, also gives an idea about seroprevalence of Hepatitis B infection in the community.
The prevalence of hepatitis B virus was more in coastal parts of Karnataka as compare to other areas. The results of these prevalence studies should helps in improving public health and to prevent spreading of the disease in the local population. According to the WHO classification, the coastal part of Karnataka qualifies as a low prevalence area of hepatitis B infection (less than $2 \%$ ). The data providing a picture of hepatitis B infection burden in India has come from $\mathrm{HBs} A g$ seroprevalence studies along with advanced technology such as nucleic acid testing (NAT) for donor screening, other factors such as public awareness, educational and motivational programs, and mass immunization programs help in decreasing the hepatitis B infection. ${ }^{2}$

The Hepatitis B infection is one of the leading cause of morbidity and mortality not only because of the acute illness but also due to chronic hepatitis, cirrhosis and hepatocellular carcinoma. Currently, hepatitis B infection 
is transmitted through - infected mother to child at birth, contact with infected person, sexual contact with infected person and parenteral route through blood and body fluids. ${ }^{3} \mathrm{HBs} A g$ in the serum is the earliest marker of active $\mathrm{HBV}$ infection in both acute and chronic infection being detectable even before elimination of transaminases and onset of clinical illness. According to some studies to reduce risk of the transfusion transmitted infections includes; improving and proper donor selection, testing the donated blood for specific antibodies against hepatitis $B$ virus by using ELISA method. ${ }^{4}$

The safety of the blood and its components depends on a proper donor selection by sensitive screening tests to exclude the transfusion transmitted infectious agents, despite screening for HBsAg by ELISA for over 20 years, transfusion associated HBV continues to be one of the major problem in India among patients who receive multiple transfusions. The prevalence of the post transfusion Hepatitis B infection in India ranges from 1 to $5 \%{ }^{5}$ Hence here in this study, our objective is to determine the seroprevalence of $\mathrm{HBsAg}$ in the prevalence of $\mathrm{HBsAg}$ positivity among male and female blood donors.

\section{MATERIAL AND METHODS}

This retrospective study was conducted over a period of two years six months from July 2011 to December 2013 at Blood Bank of BLDE University Shri B M Patil Medical College, Hospital and Research Centre, Bijapur, Karnataka, India.

A total 7,018 voluntary and replacement blood donors were selected. This study was approved by the ethical committee of the institution. We included in this study volunteers of male and female from various blood donation camps of urban and rural population and also replacement donors of Bijapur District, Karnataka.

All donors were carefully selected for blood donation by trained personnel after a complete physical examination, vital parameters and satisfactorily answering the donor's questionnaire.

Assess HBsAg by using ELISA method (Tulip group and Erba Lisa 96 tests kit) (sensitivity 100\%) (If OD exceeds 2.5 or 3 or more and negative control value is $<0.1$ ) and alternatively Hepacard spot kit (Diagnostic enterprises S-MB/09/46) were used for screening the donors.

\section{Inclusion criteria}

Donors who fulfill all donation criteria recommended by FDA.

\section{Exclusion criteria}

Donors who do not fulfill all donation criteria recommended by FDA.

\section{RESULT}

Out of the total 7,018 blood donors 5,936 (84.6\%) were males and 1,082 (15.41\%) were females, shown in (Table 1). We observed that seroprevalence of HBV was higher in male donors i.e. $138(7.7 \%)$ than in female donors i.e. 01 $(0.3 \%)$, (Table 2$)$. Out of total blood donors 139 donors were positive for $\mathrm{HBsAg}$ in that 112 donors were $\leq 40$ years of age and 27 donors were $>40$ years of age (Table 3 ).

Figure 1 shows the distribution of male and female blood donors at three different time points. It is evident here that proportion of males is more than three times the females in 2011 while this rose to more than four times in 2012 and 2013.

Figure 2 shows incidence of $\mathrm{HBsAg}$ positive among male blood donors is more frequent than among female blood donors over the time. It is showing that among males the incidence of HBsAg positive is increased from 2011 to 2012 while it declined from 2012 to 2013 . The incidence of HBsAg positive among females is very few and also showing declining trend over the time.

112 donors were $\leq 40$ years of age and 27 donors were $>40$ years of age (Table 3 ).

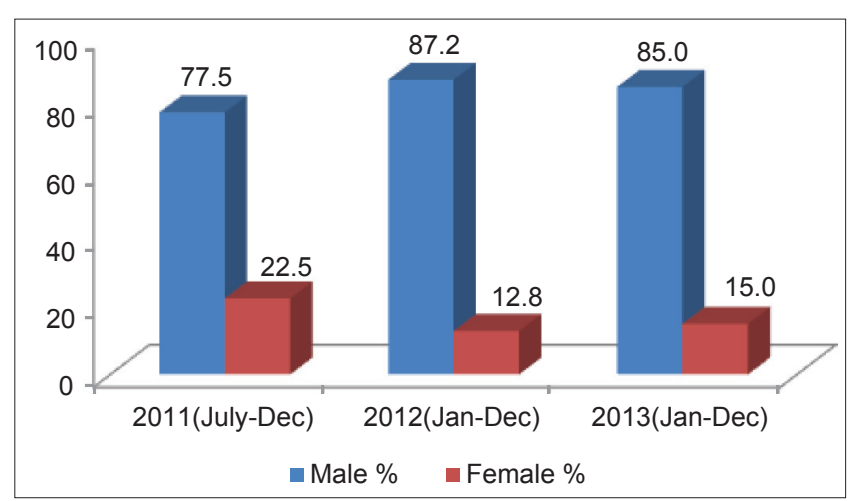

Figure 1: Percentage of blood donors during 1-7-2011 to 31-12- 2013

\begin{tabular}{|c|c|c|c|}
\hline $\begin{array}{l}\text { Study period } \\
2 \text { years } 6 \text { months }\end{array}$ & $\begin{array}{l}\text { Total } \\
\text { donors }\end{array}$ & $\begin{array}{l}\text { Male } \\
\text { donors }\end{array}$ & $\begin{array}{l}\text { Female } \\
\text { donors }\end{array}$ \\
\hline 2011(July to Dec) & 1113 & 863 & 250 \\
\hline 2012(Jan to Dec) & 2422 & 2111 & 311 \\
\hline 2013(Jan to Dec) & 3483 & 2962 & 521 \\
\hline 2 years, 6 months & 7,018 & 5,936 & 1,082 \\
\hline
\end{tabular}




\begin{tabular}{lcccc}
\hline \multicolumn{4}{l}{ Table 2: Incidence of HBsAg among male and female donors during period of 1-07-2011 to 31-12-2013 } \\
\hline $\begin{array}{l}\text { Study period } \\
\mathbf{2} \text { years } \mathbf{6} \text { months }\end{array}$ & $\begin{array}{c}\text { HBsAg positive } \\
\text { in male donors }\end{array}$ & $\begin{array}{c}\text { HBsAg positive } \\
\text { in female donors }\end{array}$ & $\begin{array}{c}\text { Total number of } \\
\text { HBsAg positive cases }\end{array}$ & $\begin{array}{c}\text { \% of total number of } \\
\text { HBsAg positive cases }\end{array}$ \\
\hline 2011(July to Dec) & 24 & 00 & 24 & 2.2 \\
2012(Jan to Dec) & 62 & 01 & 63 & 2.6 \\
2013(Jan to Dec & 52 & 00 & 52 & 1.5 \\
Total & 138 & 01 & 139 & 6.3 \\
\hline
\end{tabular}

\begin{tabular}{lcc}
$\begin{array}{l}\text { Table 3: Showing distribution of donors } \\
\text { according age }\end{array}$ \\
\hline No. & Age & HBsAg \\
\hline 1 & $19-24$ & 35 \\
2 & $25-30$ & 25 \\
3 & $31-35$ & 32 \\
4 & $36-40$ & 20 \\
5 & $41-45$ & 18 \\
6 & $46-50$ & 09 \\
\hline
\end{tabular}

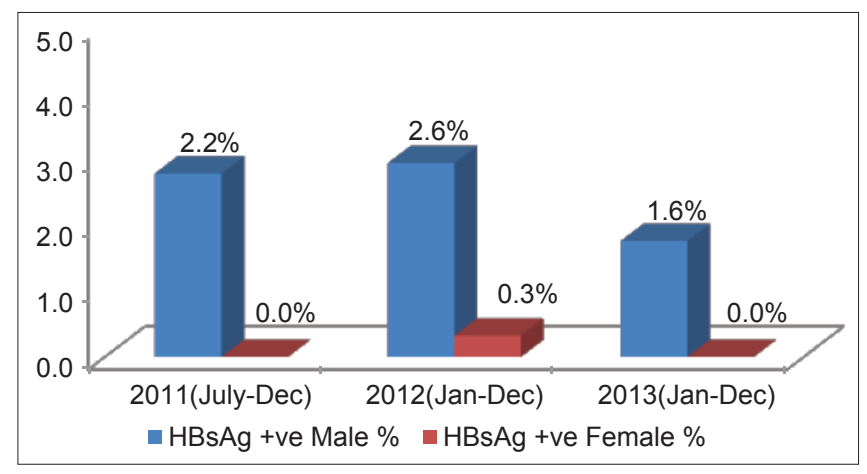

Figure 2: Showing incidence of $\mathrm{HBsAg}$ among male and female donors during Period of 1-07-2011 to 31-12-2013

In our study we observed that seroprevalence of Hepatitis $\mathrm{B}$ infection is more prevalent in younger age group and predominantly in male donors.

\section{DISCUSSION}

Hepatitis B is one of the most common transfusion transmissible infections. The prevalence of this infection varies across the different geographical regions. Noting the trend of seroprevalence of hepatitis B is useful to assist the preventive strategies. The aim of this study was to determine the trend of seroprevalence of hepatitis B in Bijapur District, Karnataka over a period of two years six months.

Glynn SA et al in their study stated that Hepatitis B infection is one of the major health problem which affects two Billions of people throughout worldwide and 350 million people suffer from the chronic HBV infection. ${ }^{4}$ In India the prevalence of the Hepatitis B infection is 4\% in the general population, which means that 40 million people are infected with hepatitis $\mathrm{B}$ infection. ${ }^{5}$
Schmidt $\mathrm{M}$ et al in their study found that, prevalence of the $\mathrm{HBV}$ infection in the voluntary blood donors is $1-3 \%$ and $0-12 \%$ in the commercial donors. 6 In our study, among the 7,018 blood donors screened, the overall seroprevalence of HBsAg was observed to be $1.32 \%$.

Chandrasekaran S \& Karki S et al in their study found that seroprevalence of hepatitis B infection was significantly high in male donors as compared to female donors. As in our study also seroprevalence of hepatitis B infection among male donors was significantly high there was no significant difference in the prevalence rates of $\mathrm{HBsAg}$ seropositivity among male and female donors in our study because male donors are predominant compared to female donors. ${ }^{7,8}$

Rodenas et al reported in their study higher prevalence of HBsAg positivity in donors older than 38 years. ${ }^{9}$ In our study we found that the majority of seropositive $\mathrm{HBsAg}$ donors were younger than 40 years.

Many studies reported that seroprevalence of hepatitis B infection higher in males than in females. Singh $\mathrm{K}$ et al screened, 30,428 blood donors the overall seroprevalence of $\mathrm{HBsAg}$ was observed to be $0.62 \%$ out of the total 30,428 blood donors, $28,046 \quad(92.17 \%)$ were males and $2,382(7.83 \%)$ were females with male to female ratio of 11.77:1. A higher seroprevalence rate was observed among male donors than in female blood donors $(0.65 \%$ versus $0.25 \%$ respectively). ${ }^{2}$

Chowdhury A et al in their study they compared the demographic characteristics of the participants with the among general population of Birbhum district as well as West Bengal the participation rate among female subjects (83.88\%) was lower than that of male subjects $(90.15 \%) .{ }^{10}$ In our study we screened for Hepatitis B infection of total of 7,018 donors including both male and female donors of which we reported that 139 donors were seropositive for $\mathrm{HBs} \mathrm{Ag}$.

Lavanya $\mathrm{V}$ et al screened a total of 200 blood donors during their study among them a vast majority was males (184: $92 \%$ ), male to female ratio of $11.5: 1$. Out of the 200 samples studied, 7 of them were found to be positive for HBsAg. The prevalence rate of HBsAg was (7/200) 3.5\%. All the positive cases were male and no female donors were found 
to be positive for HBsAg. Age wise prevalence was found to be more in 31 to 35 years group. ${ }^{11}$ In this study age wise distribution we found high seroprevalence of hepatitis B infection in younger age group between 19 to 40 years group.

Karki $S$ et al in their study reported that the seroprevalence of hepatitis B infection high in male donors as compared to female donors, but in their study the majority of blood donors were males. The statistical analysis (chi-square test) shows significant difference in the seroprevalence of hepatitis B Infection ( $p$ value -0.024). ${ }^{8}$

In our study male donors were predominant total 5,936 compared to female donors 1,082 we also observed a higher seroprevalence rate among male donors than in female blood donors. Nilima S et al screened a total of 5008 blood donors in three years. The number of blood donors has been increased from 1101 donors in 2006, 1868 donors in 2007 and 2039 in year 2008. In their study they observed that there was a gradual increase in seropositive samples of HBsAg in last three years that was $29(2.6 \%)$ in 2006, 50 $(2.67 \%)$ in 2007, and $70(3.43 \%)$ in 2008 whereas decline was noticed for HCV, HIV, and VDRL. ${ }^{12}$

In our study we observed that seroprevalence hepatitis B infection was more prevalent compared to other transfusion transmitted infection, especially among younger age group.

\section{CONCLUSION}

Seroprevalence hepatitis B infection was more prevalent compared to other transfusion transmitted infection, especially among younger age group and will continue to do so as long as commercial blood banks remain operational and until appropriate nationwide vaccination programmes and other control measures are established. The increasing prevalence of HBsAg can be reduced by more sensitive screening assays and proper donor selection.

\section{ACKNOWLEDGEMENTS}

I am thankful to all technicians and nursing staff of Blood Bank for technical assistance Department of Pathology,
BLDE university Shri B. M. Patil Medical College, Hospital \& Research Center, Bijapur, Karnataka, India for their support in completion of my work Successfully.

\section{REFERENCES}

1. Prevention of hepatitis B in India, An overview. World Health Organizaton. New Delhi ; 2002.

2. Singh $\mathrm{K}$, Bhat $\mathrm{S}$ and Shastry $\mathrm{S}$. Trend in seroprevalence of Hepatitis B virus infection among blood donors of coastal Karnataka, India. JIDC 2009; 3(5): 376-379.

3. WHO global health situation projection and estimates 1992 ; WHO Geneva.

4. Glynn SA, Kleinman SH, Wright DJ and Busch MP. International Application of the incidence rate and window period model (editorial). National Heart Lung and Blood Institute Retrovirus Epidemiology Donor Study Transfusion 2002; 42: 966-973.

5. Bharat $S$, Monika $V$ and Karttikaye $V$. The markers for transfusionassociated hepatitis in north Indian blood donors: the prevalence and the trends. Jpn J Infect Dis 2004; 57:49-51.

6. Schmidt M, Nübling $\mathrm{CM}$, Scheiblauer $\mathrm{H}$, Chudy M, Walch LA, Seifried $\mathrm{E}$, et al. The anti-HBc screening of blood donors: a comparison of nine anti-HBc tests. Vox Sanguinis 2006; 91:237-243.

7. Chandrasekaran S, Palaniappan N, Krishnan V, Mohan G and Chandrasekaran N. Relative prevalence of hepatitis B viral markers and hepatitis $\mathrm{C}$ virus antibodies (anti HCV) in Madurai, South India. Indian J Med Sci 2000; 54:270-273.

8. Karki S, Ghimire P, Tiwari BR and Rajkarnikar M. HBsAg sero surveillance among Nepalese blood donors. Annals of Tropical Medicine and Public Health 2008; 1:15-18.

9. Rodenas JG, Bacasen LC and Que ER. The prevalence of $\mathrm{HBsAg}(+)$ and anti $\mathrm{HCV}(+)$ among healthy blood donors at east avenue medical center, Quezo city. Phil J of Gastroenterology 2006; 2: 64-70.

10. Chowdhury A, Santra A, Chakravorty R, Banerji A, Pal S, Dhali GK, et al. Community-based epidemiology of hepatitis $B$ virus infection in West Bengal, India: prevalence of hepatitis B e antigen-negative infection and associated viral variants. J Gastroenterol Hepatol 2005; 20(11):1717-1720.

11. Lavanya V, Viswanathan $T$, Arul Sheeba MS, Malarvizhi A and Moorthy K. Prevalence of hepatitis B virus infection among blood donors with antibodies to hepatitis B core antigen. International Journal of Medicine and Medical Sciences 2012;4(6),128-137.

12. Karki S, Ghimire P, Tiwari BR and Rajkarnikar M. HBsAg serosurveillance among. Nepalese blood donors. Annals of Tropical Medicine and Public Health 2008; 1: 15-18.

13. Nilima S, Sawke GK and Chawla S. Seroprevalence Of Common Transfusion - Transmitted infections among Blood Donors. People's Journal of Scientific Research 2010;.3(1): 5-6.

\section{Authors Contribution:}

PMP - designed the study, analysed the data and reviewed the manuscript; VSP - designed the study; BRY - reviewed the manuscript; BG - contributed to the study design; MJB - designed the study and analysed the data; MRG and MS - Contributed to the statistical analysed the data. 